(6) OPEN ACCESS

\title{
Exposure to genocide and risk of suicide in Rwanda: a population-based case-control study
}

\author{
Wilson Rubanzana, ${ }^{1,2}$ Bethany L Hedt-Gauthier, ${ }^{1,3}$ Joseph Ntaganira, ${ }^{1}$ \\ Michael D Freeman ${ }^{4,5,6}$
}

- Additional material is published online only. To view please visit the journal online (http://dx.doi.org/10.1136/jech2014-204307).

For numbered affiliations see end of article.

\section{Correspondence to}

Dr Wilson Rubanzana, Rwanda University, College of Medicine and Health Sciences, School of Public Health. P.O. Box: 5229

Kigali, Rwanda;

wrubanzana@nursph.org

Received 5 May 2014 Revised 14 August 2014 Accepted 23 August 2014 Published Online First 8 December 2014

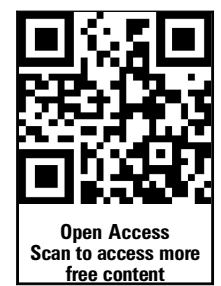

CrossMark

\begin{tabular}{|l|}
\hline To cite: Rubanzana W, \\
Hedt-Gauthier BL, \\
Ntaganira J, et al. J \\
Epidemiol Community Health \\
2015;69:117-122. \\
\hline
\end{tabular}

\section{ABSTRACT}

Background In Rwanda, an estimated one million people were killed during the 1994 genocide, leaving the country shattered and social fabric destroyed. Largescale traumatic events such as wars and genocides have been linked to endemic post-traumatic stress disorder, depression and suicidality. The study objective was to investigate whether the 1994 genocide exposure is associated with suicide in Rwanda.

Methods We conducted a population-based casecontrol study. Suicide victims were matched to three living controls for sex, age and residential location. Exposure was defined as being a genocide survivor, having suffered physical/sexual abuse in the genocide, losing a first-degree relative in the genocide, having been convicted for genocide crimes or having a firstdegree relative convicted for genocide. From May 2011 to May 2013, 162 cases and 486 controls were enrolled countrywide. Information was collected from the police, local village administrators and family members.

Results After adjusting for potential confounders, having been convicted for genocide crimes was a significant predictor for suicide (OR=17.3, 95\% Cl 3.4 to 88.1). Being a survivor, having been physically or sexually abused during the genocide, and having lost a first-degree family member to genocide were not significantly associated with suicide.

Conclusions These findings demonstrate that individuals convicted for genocide crimes are experiencing continued psychological disturbances that affect their social reintegration into the community even 20 years after the event. Given the large number of genocide perpetrators reintegrated after criminal courts and Gacaca traditional reconciling trials, suicide could become a serious public health burden if preventive remedial action is not identified.

\section{INTRODUCTION}

In Rwanda, the 1994 genocide against the Tutsi resulted in the mass murder of approximately one million people over a period of 100 days. ${ }^{12}$ The genocide left the people of Rwanda traumatised, both physically and mentally, and disrupted the social fabric of the country. Current Rwandan residents were affected by the genocide to various degrees, including individuals who were survivors of the genocide (primarily individuals living in Rwanda in 1994 who were targeted due to their Tutsi ethnicity) and individuals who were perpetrators of the genocide (Hutu extremist who carried out the genocidal activities). Reconciliation efforts facilitated by the Gacaca trial systems (a traditional mechanism that was used by Rwandan communities to resolve disputes) has largely reintegrated genocide perpetrators into Rwandan society. ${ }^{3}$ The result is that the degree of personal genocide exposure among the current Rwandan population ranges from none at all to surviving victims and perpetrators, all living in the same communities.

A number of prior studieshave described an association between large-scaletraumatic events, such as war and genocide, and post-traumatic stress disorder, depression and suicidal ideation..$^{5-7}$ These findings appear to hold true in Rwanda, where it has been estimatedthat $53 \%$ of the postgenocidal population show symptoms of post-traumatic stressdisorder and/or depression. ${ }^{8}$ However, research regarding exposure to genocide and completedsuicideis limited. Aside from studies of Jewish Holocaust survivors demonstrating an increased rate of suicide, ${ }^{9}{ }^{10}$ we have found no additional literature on suicide rates of survivors of other genocides. Even less is known about the lasting effects on genocide perpetrators; to our knowledge, the relationship between a history of genocide perpetration and risk of suicide has never been studied.

In Rwanda, little is known about suicide. The only reliable source of information in Rwanda is law enforcement organisations, specifically the police, created in 2000. Prior to 2000, data on suicide were non-existent and even today, no comprehensive surveillance system of suicide deaths exists. In this study, we explore the lingering effects of genocide as a risk factor for suicide in Rwanda. We considered five categories of genocide exposure: genocide survivor, physically and/or sexually abused during genocide, loss of a first-degree relative to genocide, convicted of genocide crimes and first-degree family member convicted of genocide crimes. The objective of this study is to investigate whether the type and degree of exposure to the 1994 genocide is associated with completed suicide in Rwanda. Such information may be used in the development of evidence-based public health interventions aimed at reducing the incidence of suicide in the country.

\section{METHODS}

\section{Study design and population}

We conducted a population-based case-control study. Study participants were selected from all 30 districts of Rwanda. From May 2011 to May 2013, 162 cases and 486 controls were enrolled countrywide. Only fully investigated suicides of Rwandan citizens aged 18 and older were included into this study. Cases were identified via daily reports of unnatural deaths gathered and maintained by the Rwanda National Police Commission of Operations. Exclusion criteria included unconfirmed/unclear 
case of suicide, inability to identify the decedent and inability to trace family members of the deceased. Suicides that met the inclusion criteria were further investigated with a trained study interviewer who ascertained the identification and residence of the victim at the police station that investigated the case and thereafter proceeded to the victim's household to collect information on the manner and circumstances of suicide and personal and family background information.

Controls were selected from living residents, 18 years of age and older, individually matched to cases by sex, age ( \pm 5 years) and residential location. Controls were identified with the assistance of local village administrators who were blinded to the aim of the study and who were asked to select three people meeting the matching criteria.

\section{Sources of data}

Information was collected from the police, local village administrators and family members. In some cases, we found next of kin who did not have some information (eg, the exact age or the level of education of the case or control), and other family members were interviewed. The decedent's next of kin were identified via the assistance of village administrators; information was collected within 1 week of the date of the suicide for both cases and the matched controls. The principal investigator (WR) reviewed all questionnaires for quality control and accuracy of data entry.

The interviews were conducted by nurses, who received in-depth training on criminal investigation and counselling given the sensitive nature of the questions. The family interviews were conducted carefully and respectfully, particularly with regard to questions related to the genocide. Owing to concern of underreporting of exposure, particularly for those who had been tried in Gacaca, when responses were deemed to be contradictory or deceptive, local police and administrators who have access to official registers were consulted.

\section{Data collection and variables}

A pilot-tested questionnaire was administered to the next of kin of cases as well as controls. The questionnaire was designed in English and then translated into Kinyarwanda (see online supplementary materials). The questionnaire consisted of two parts; the first part was only applicable to the cases and included relevant information on the specific characteristics of the suicide. The second part, collected on both cases and controls, included sociodemographic characteristics, history of alcohol and drug use, history of mental illness, the diagnosis of a lifethreatening disease within the past 6 months (HIV-AIDS, tuberculosis, cancer, malaria and others), feelings of loneliness within the prior 3 months, past criminal record and a personal or family history of suicidality.

The primary exposures considered were as follows. A survivor was defined as a Rwandan who was living in Rwanda during the genocide period (6 April-4 July 1994), in governmentcontrolled territories and who was of Tutsi ethnicity. This aligns with the Government of Rwanda definition of survivor ${ }^{11}$ and United Nations resolution 2136 on DRC sanctions. ${ }^{12}$ A perpetrator in the 1994 genocide was an individual who had been convicted of a genocide crime either in Gacaca or criminal court. Additional exposures included if the study participant had been physically, sexually and/or emotionally abused during the genocide, had lost a first-degree relative to the genocide or had a first-degree relative convicted of genocide in Gacaca or criminal courts.

\section{Statistical analysis}

A sample size calculation indicated a minimum sample of 150 cases matched with 450 controls with an anticipated OR of 2.0, assuming a control population exposure probability of $50 \%$, with $95 \%$ power to detect a difference and 5\% $\alpha$-error for a two-sided test. The distribution and circumstances of suicide were examined with descriptive statistics. Conditional logistic regression modelling was used to identify risk factors for suicide. First, univariable logistic regression models were fitted for all potential confounding factors. Next, a Mantel-Haenszel test of homogeneity was used to identify interactions between confounders and primary exposures to include in the model.

Finally, multivariable conditional logistic regression was used to assess the association between each potential hypothetical genocide exposure variable and suicide. Each exposure category was modelled separately. All models were controlled for potential confounders that were considered in the study design based on the existing literature and the investigator conceptual framework. Suicidal ideation was excluded from the multivariable analysis because it was on the suicide causal pathway. Matching variables, namely age, sex and village of residence, were not included in the conditional logistic regression models. The statistical analysis was performed using STATA V.11.2 (StataCorp, College Station, Texas, USA).

\section{Ethics}

Informed verbal consent was sought and obtained from study participants (for controls) and next of kin before their participation in the study. We opted for oral consent because of low literacy in rural Rwanda. All informations were kept in a secure location and data analysis was performed on a de-identified data set. The study was sponsored by the WHO, which had no role in study design, data collection, data management, data analysis and interpretation, the writing of the paper or its submission for publication.

\section{RESULTS}

Of the 162 cases of suicide that were investigated, $125(77.2 \%)$ were male and $37(22.8 \%)$ were female. The most common method of suicide was hanging with 97 cases (59.9\%), followed by poisoning, 49 (30.3\%); drowning, 9 (5.6\%) and suicide by other methods (use of a spear, gunshot wounds and self immolation), 7 (4.2\%). The majority of suicides, 117 (72.3\%), took place at the home of the deceased (table 1). Of the suicide cases investigated, $24(14.3 \%)$ were convicted for genocide, 16 $(9.5 \%)$ were Tutsi genocide survivors and $1(0.6 \%)$ was a moderate Hutu who was threatened during the genocide. The remaining 121 (75.6\%) were people who were not classified as either a survivor or having been convicted for the 1994 genocide crimes according to the study definitions (table 1).

In the univariable analysis, there was a significant difference between the proportions of people who had been convicted of genocide by Gacaca or criminal courts among suicide victims (14.8\%) compared with controls $(5.8 \%$; OR $=3.5$, 95\% CI 1.8 to $6.9, \mathrm{p}<0.001)$. In contrast, there were no significant differences in the proportions of individuals who had first-degree family members who had been found guilty of genocide crimes between suicide victims and controls. No significant differences were found in the frequency of genocide survivors or having been physically or sexually abused during the genocide between suicide victims and controls. On the contrary, the frequency of having lost a first-degree relative to the genocide was 
Table 1 Description of suicide characteristics in Rwanda $(N=162)$

\begin{tabular}{|c|c|c|}
\hline Characteristic & $\mathrm{N}$ & Per cent \\
\hline \multicolumn{3}{|l|}{ Gender } \\
\hline Male & 125 & 77.8 \\
\hline Female & 37 & 22.8 \\
\hline \multicolumn{3}{|l|}{ Age group (years)* } \\
\hline$<20$ & 2 & 1.2 \\
\hline $20-29$ & 33 & 20.4 \\
\hline $30-39$ & 47 & 29 \\
\hline $40-49$ & 16 & 9.9 \\
\hline $50-59$ & 27 & 16.7 \\
\hline$\geq 60$ & 37 & 22.8 \\
\hline \multicolumn{3}{|l|}{ Province } \\
\hline Kigali & 29 & 17.9 \\
\hline Eastern & 52 & 32.1 \\
\hline Southern & 32 & 19.8 \\
\hline Northern & 36 & 22.2 \\
\hline Western & 29 & 17.9 \\
\hline \multicolumn{3}{|l|}{ Area of residence } \\
\hline Towns/cities & 25 & 15.4 \\
\hline Rural & 137 & 84.6 \\
\hline \multicolumn{3}{|l|}{ Site of death } \\
\hline Home & 117 & 72.3 \\
\hline Neighborhood (village) & 29 & 17.9 \\
\hline Away from the village of residence & 16 & 9.8 \\
\hline \multicolumn{3}{|l|}{ Method of suicide } \\
\hline Hanging & 97 & 59.9 \\
\hline Poisoning & 49 & 30.3 \\
\hline Drowning & 9 & 5.6 \\
\hline Other (homemade spear, gunshot and self-immolation) & 7 & 4.2 \\
\hline \multicolumn{3}{|l|}{ Medicolegal postmortem } \\
\hline Performed & 136 & 84 \\
\hline Not performed & 26 & 16 \\
\hline \multicolumn{3}{|l|}{ Alleged motive of suicide } \\
\hline Family feud & 49 & 30.3 \\
\hline Jealousy & 30 & 18.5 \\
\hline Mental illness & 24 & 14.8 \\
\hline Land or money dispute & 20 & 12.4 \\
\hline Chronic disease & 12 & 7.4 \\
\hline Other (postpartum depression, sexual impotence) & 2 & 1.2 \\
\hline Unknown & 25 & 15.4 \\
\hline
\end{tabular}

*Age at time of study. Data collection occurred approximately 18 years after the genocide.

significantly lower in the cases $(8.6 \%)$ than the controls $(15.2 \%)$ $(\mathrm{OR}=0.5,95 \%$ CI 0.3 to $0.9, \mathrm{p}=0.029$; table 2$)$.

There were significant differences between cases and controls for a range of sociodemographic, psychological, clinical and criminological risk factors. Factors that significantly increased risk of suicide included a history of divorce, polygamy, living alone, 'other' employment status (encompassing categories of people not working for known reasons such as being a student, or being a disabled or retired person), a recent diagnosis of a chronic disease, moderate to heavy alcohol and drug use, suicidal ideation, previous suicide attempts, a family history of suicide and a history of criminal activity (table 3). Education was found to be protective against suicide. No significant interactions between these risk factors and genocide exposure groups were found.

In the multivariable analysis, after adjusting for all significant covariates, none of the genocide survivor characteristics were
Table 2 Univariate conditional logistic regression analysis of hypothesised genocide risk factors among suicide cases $(\mathrm{N}=162)$ compared with living controls $(\mathrm{N}=486)$

\begin{tabular}{|c|c|c|c|c|}
\hline Characteristics & $\begin{array}{l}\text { Cases } \\
\mathrm{N}(\%)\end{array}$ & $\begin{array}{l}\text { Controls } \\
\mathrm{N}(\%)\end{array}$ & $\begin{array}{l}\text { ORs } \\
(95 \% \mathrm{Cl})\end{array}$ & p Value \\
\hline \multicolumn{5}{|c|}{ Being a genocide survivor } \\
\hline No & $146(90.1)$ & $414(85.2)$ & 1 & \\
\hline Yes & $16(9.9)$ & $72(14.8)$ & $0.6(0.3$ to 1.1$)$ & 0.099 \\
\hline \multicolumn{5}{|c|}{ Physically or sexually abused during genocide } \\
\hline No & $153(96.2)$ & $454(93.6)$ & 1 & \\
\hline Yes & $6(3.8)$ & $31(6.4)$ & $0.5(0.2$ to 1.4$)$ & 0.182 \\
\hline \multicolumn{5}{|c|}{ Lost first-degree relative to genocide } \\
\hline No & $148(91.4)$ & $412(84.8)$ & 1 & \\
\hline Yes & $14(8.6)$ & $74(15.2)$ & $0.5(0.3$ to 0.9$)$ & 0.029 \\
\hline \multicolumn{5}{|c|}{ Having been convicted of genocide } \\
\hline No & $138(85.2)$ & $455(94.2)$ & 1 & \\
\hline Yes & $24(14.8)$ & $28(5.8)$ & 3.5 (1.8 to 6.9$)$ & $<0.001$ \\
\hline \multicolumn{5}{|c|}{ Having a first-degree relative who has been convicted of genocide } \\
\hline No & $142(88.2)$ & $439(91.8)$ & 1 & \\
\hline Yes & $19(11.8)$ & $39(8.2)$ & $1.6(0.8$ to 3.0$)$ & 0.131 \\
\hline
\end{tabular}

associated with risk of suicide (table 4). The only genocide-related variable that was associated with high risk of suicide was having been convicted for genocide-related crimes $(\mathrm{OR}=17.3,95 \%$ CI 3.4 to $88.1, \mathrm{p}=0.001)$.

\section{DISCUSSION}

Our results demonstrated, rather surprisingly, that genocide survival was not associated with a higher risk of committing suicide in Rwanda. Indeed, all of the categories of survivors demonstrated a decrease in suicide risk, although the association was only marginally significant for individuals who lost a first-degree relative in the genocide. These findings differ dramatically from the results of a community-based study, carried out in four sectors of the Muhanga district, in the Southern province of Rwanda that showed $25 \%$ of survivors enrolled in that survey presented with suicidal tendencies. ${ }^{13}$ Similarly, our findings are in discordance with what has been reported previously, particularly in studies of Jewish Holocaust survivors. Extremely high rates of suicide have been reported among Jewish survivors of persecution associated with World War II, particularly among those who were interned in ghettos and concentration camps. ${ }^{14}$ Other authors have described high rates of suicidal ideation in Holocaust survivors living in Canada andIsrael. ${ }^{9} 10$ High rates of suicide have also been reported in populations of survivors of cultural genocide among indigenous people in Australia and Canada. ${ }^{15}$

There are at least two plausible explanations for the unique findings in Rwanda. First, following the genocide the Rwandan government implemented a number of social programmes designed to improve the socioeconomic situation of genocide survivors. These programmes include FARG (genocide survivors assistance fund), a fund for the provision of assistance to child survivors, and survivor organisations such as IBUKA (umbrella of genocide survivors associations) and AVEGA Agahozo (genocide survivors widows' association), among others. The high degree of contact and support available to survivors has likely served as a deterrent to suicide. A second explanation is survivor bias, which postulates that it is reasonable to presume genocide survivors with the highest propensity for suicide died in the 
Table 3 Univariate conditional logistic regression analysis of sociodemographic, clinical, psychological and criminological characteristics among suicide cases $(\mathrm{N}=162)$ and living controls $(\mathrm{N}=486)$

\begin{tabular}{|c|c|c|c|c|}
\hline Characteristics & $\begin{array}{l}\text { Cases } \\
\mathrm{N}(\%)\end{array}$ & $\begin{array}{l}\text { Controls } \\
\mathrm{N}(\%)\end{array}$ & $\begin{array}{l}\text { Crude ORs } \\
95 \%(\mathrm{Cl})\end{array}$ & $\mathrm{p}$ Value \\
\hline \multicolumn{5}{|l|}{ Sociodemographic characteristics } \\
\hline \multicolumn{5}{|l|}{ Marital status } \\
\hline Single & $33(20.4)$ & $113(23.3)$ & 1 & \\
\hline Married & 89 (54.9) & $314(64.6)$ & $1.1(0.6$ to 2.4$)$ & 0.724 \\
\hline Widowed & $10(6.2)$ & $25(5.1)$ & 1.7 (0.6 to 5.5$)$ & 0.34 \\
\hline Divorced & $8(4.9)$ & $7(1.4)$ & 4.7 (1.6 to 15.3$)$ & 0.011 \\
\hline Polygamous & $22(13.6)$ & $27(5.6)$ & $4.3(1.6$ to 11.2$)$ & 0.003 \\
\hline \multicolumn{5}{|l|}{ Parenthood status } \\
\hline No & $43(26.5)$ & $112(23.1)$ & 1 & \\
\hline Yes & $119(73.5)$ & $374(76.9)$ & $0.6(0.3$ to 1.2$)$ & 0.161 \\
\hline \multicolumn{5}{|l|}{ Living alone } \\
\hline No & $132(81.9)$ & $435(89.5)$ & 1 & \\
\hline Yes & $30(18.1)$ & $51(10.5)$ & $2.1(1.2$ to 3.7$)$ & 0.006 \\
\hline \multicolumn{5}{|l|}{ Religion } \\
\hline None & $20(12.4)$ & $38(8.0)$ & 1 & \\
\hline Christian & $138(85.7)$ & $431(90.7)$ & $0.6(0.3$ to 1.0$)$ & 0.064 \\
\hline Muslim & $3(1.9)$ & $6(1.3)$ & $1.1(0.17$ to 6.6$)$ & 0.945 \\
\hline \multicolumn{5}{|l|}{ Education level } \\
\hline None & $58(36.3)$ & $120(24.8)$ & 1 & \\
\hline Primary & $86(53.7)$ & $306(63.4)$ & $0.4(0.2$ to 0.7$)$ & 0.001 \\
\hline Secondary or tertiary & $16(10.0)$ & 57 (11.8) & $0.3(0.14$ to 0.8$)$ & 0.03 \\
\hline \multicolumn{5}{|l|}{ Employment status } \\
\hline Employed & $118(72.8)$ & $386(79.6)$ & 1 & \\
\hline Dealing in illegal activities & $4(2.5)$ & $10(2.0)$ & $1.8(0.4$ to 7.6$)$ & 0.421 \\
\hline Unemployed & $17(10.5)$ & $42(8.7)$ & 2.1 (0.9 to 4.9$)$ & 0.102 \\
\hline Other & $23(14.2)$ & $47(9.7)$ & $4.2(1.6$ to 11.3$)$ & 0.004 \\
\hline \multicolumn{5}{|l|}{ Clinical characteristics } \\
\hline \multicolumn{5}{|l|}{ Diagnosed with a chronic disease in the past 6 months } \\
\hline No & $106(65.8)$ & $386(79.7)$ & 1 & \\
\hline Yes & $55(34.2)$ & $98(20.3)$ & $2.3(1.9$ to 3.5$)$ & 0.002 \\
\hline \multicolumn{5}{|l|}{ Psychological characteristics } \\
\hline \multicolumn{5}{|l|}{ Alcohol drinking patterns } \\
\hline Don't drink & $39(24.2)$ & $191(39.3)$ & 1 & \\
\hline Drink slightly (1 day of drinking/week) & $36(22.4)$ & $152(31.3)$ & $1.2(0.7$ to 2.2$)$ & 0.551 \\
\hline Drink moderately (2-3 days of drinking/week) & $44(27.3)$ & $122(25.1)$ & $2.4(1.3$ to 4.3$)$ & 0.004 \\
\hline Drink heavily ( $\geq 4$ days of drink/week) & $42(26.1)$ & $21(4.3)$ & $15.1(6.9$ to 32.6$)$ & $<0.001$ \\
\hline \multicolumn{5}{|l|}{ Feeling of loneliness in the past 3 months } \\
\hline No & $105(64.8)$ & $419(86.4)$ & 1 & \\
\hline Yes & $57(35.2)$ & 66 (13.6) & $4.0(2.6$ to 6.8$)$ & $<0.001$ \\
\hline \multicolumn{5}{|l|}{ Known case of mental illness } \\
\hline No & $139(85.8)$ & $483(99.8)$ & 1 & \\
\hline Yes & $23(14.2)$ & $1(0.2)$ & - & - \\
\hline \multicolumn{5}{|l|}{ Had expressed suicide ideation in the past 3 months } \\
\hline No & 87 (57.6) & $446(95.1)$ & 1 & \\
\hline Yes & $64(42.4)$ & $23(4.9)$ & 16.7 (8.6 to 32.9$)$ & $<0.001$ \\
\hline \multicolumn{5}{|l|}{ Had made a suicide attempt } \\
\hline No & $123(76.4)$ & 471 (99.2) & 1 & \\
\hline Yes & $38(23.6)$ & $4(0.8)$ & 54.2 (13.0 to 224.9$)$ & $<0.001$ \\
\hline \multicolumn{5}{|l|}{ Family history of suicide } \\
\hline No & $93(61.6)$ & $338(86.0)$ & 1 & \\
\hline Yes & $58(38.4)$ & $63(14.0)$ & $4.4(2.7$ to 7.0$)$ & $<0.001$ \\
\hline \multicolumn{5}{|l|}{ Criminological characteristics } \\
\hline Past criminal record, other than genocide & & & & \\
\hline No & $125(77.6)$ & $451(92.8)$ & 1 & \\
\hline Yes & $36(22.4)$ & $35(7.2)$ & 5.6 (3.0 to 10.7$)$ & $<0.001$ \\
\hline Known drug user & & & & \\
\hline No & $112(77.8)$ & $436(95.8)$ & 1 & \\
\hline Yes & $32(22.2)$ & $19(4.2)$ & 11.5 (5.0 to 26.3$)$ & $<0.001$ \\
\hline
\end{tabular}


months and years directly following 1994. The result would be that the current population of genocide survivors is, in fact, more resistant to suicide than other groups. However, studies on the Holocaust have shown that suicide risk can still be high even many years after exposure. ${ }^{9} 10$

In contrast with the finding of lowered suicide risk for survivors, we found a higher risk of suicide among individuals convicted for genocide crimes (genocide perpetrators). Our findings are in line with the results of a survey in Muhanga district, Southern province, which revealed that $7 \%$ of former prisoners, who were convicted for their participation in genocide, presented with suicidal tendencies. ${ }^{13}$ The most obvious explanation for our findings is the lifelong stigma that presumably accompanies the commission of the atrocities that are associated with genocide, particularly one of such a massive scale. There is evidence of an increased level of guilt among Rwandan perpetrators, ${ }^{13}$ and further examination of this subpopulation is needed to assess levels of depression and acceptance by society. These psychological disturbances are likely compounded by other negative life events experienced by perpetrators, including war, poverty, family disruption, and the criminal charges and associated penalties. $^{16}$

In univariable analysis, there were a number of previously identified factors and potential confounders that were found to be significantly associated with suicide in the present study and significant factors were controlled for in the multivariate analysis. ${ }^{17-28}$ We identified a strong association between suicidal ideation in the prior 3 months and suicide, but excluded this from the multivariate model because it lay on the causal pathway between exposure and outcome.

Strengths of the present study were the population-based case-control study design, the prospective identification of cases, the large sample size and the close collaboration with police investigators who had first hand and reliable information on the suicides. There were, however, several limitations to consider as well. Selection bias in the identification of appropriate control populations is of concern in suicide case-control studies. Further, controls in this study were identified by village

Table 4 Multivariate conditional logistic regression analysis of hypothesised genocide risk factors for suicide

\begin{tabular}{|c|c|c|c|}
\hline Characteristic & Adjusted ORs & $95 \% \mathrm{Cl}$ & p Value \\
\hline \multicolumn{4}{|c|}{ Being a genocide survivor } \\
\hline No & 1 & & \\
\hline Yes & 0.4 & 0.1 to 1.2 & 0.106 \\
\hline \multicolumn{4}{|c|}{ Physically or sexually abused during genocide } \\
\hline No & 1 & & \\
\hline Yes & 0.2 & 0.1 to 1.4 & 0.115 \\
\hline \multicolumn{4}{|c|}{ Lost first-degree relative to genocide } \\
\hline No & 1 & & \\
\hline Yes & 0.4 & 0.1 to 1.2 & 0.101 \\
\hline \multicolumn{4}{|c|}{ Having been convicted of genocide } \\
\hline No & 1 & & \\
\hline Yes & 17.3 & 3.4 to 88.1 & 0.001 \\
\hline \multicolumn{4}{|c|}{ Having a first-degree relative who has been convicted of genocide } \\
\hline No & 1 & & \\
\hline Yes & 1.4 & 0.4 to 4.4 & 0.59 \\
\hline
\end{tabular}

leadership because a list for random selection was not feasible. This latter point is of concern, because it is possible that individuals who are more popular or who exhibit more positive behaviours would be selected by the village administrator. However, we believe these biases are minimised by working closely with village leadership who were blinded to the study objectives and the fact that given the small numbers in villages, few individuals would meet the matching criteria often leading to exhaustive selection of eligible controls. Another limitation is that suicide was based on police assessment and not on an official coroner report, which is currently not available in Rwanda and it is possible that some cases were mistakenly classified as suicide. In this study, $84 \%$ of suicide cases underwent postmortem examination and unclear suicide cases were excluded, so we are relatively confident that cases had indeed committed suicide.

Some recall and desirability bias may have also been introduced in the methodology of the study. Although the interviews were carried out within a week of the death, the presence of recall bias within the family likely varied due to differing frequency of contact and levels of knowledge of the study participants. Further, even though 20 years had elapsed, interviewing family members regarding the level of participation in the genocide is a delicate matter, and one that may not always elicit accurate and honest responses. When possible, village administrators were consulted to confirm whether or not an individual had been charged and convicted for a genocide-related crime. Finally, it is possible that some potential confounders were missed and not controlled for in the multivariable model. However, great care was taken during the study design phase to identify reasonable confounders and these were included here.

The nature of the 1994 genocide is unique. Many other documented genocides, for example, the genocides in Cambodia ${ }^{29}$ and Bosnia, ${ }^{30}$ were carried out by state sponsored military and paramilitary groups over a number of years. The 1994 genocide was brief (100 days) and occurred at an unprecedented rate with many of the perpetrators including neighbours, friends and even relatives operating under government directives. Ultimately, this fact may provide a partial explanation for the results seen here; despite the enormous scale of the Rwandan genocide, it was relatively short-lived, and immediately followed by a change in government and the implementation of remedial efforts directed at the survivors. The perpetrators, who often rejoined society, may be experiencing persisting social exclusion. Further study is needed to better understand the reasons for increased risk for suicide among reintegrated individuals charged with genocide for the development of effective strategies that can reduce the rate of suicide in this high-risk group. Future research will also explore general risk factors for suicide in Rwanda in order to address this pressing health issue.

\section{What is already known on this subject}

There are few studies that research the lasting relationship between genocide and suicide, and those that exist show a higher incidence of suicide among genocide survivors even decades later. The 1994 Rwanda genocide is unique because perpetrators and victims were from the same community and after the Gacaca traditional reconciling trials many perpetrators were reintegrated, living side-by-side with survivors. To our knowledge, there are no analytical studies on the association between genocide and suicide in this context. 


\section{What this study adds}

Our findings demonstrated that 20 years after the Rwandan genocide, perpetrators are at great risk of committing suicide. Surprisingly, unlike other studies, having survived the genocide was not a risk factor for suicide. This study suggests that effective psychosocial support is needed in order to achieve total reintegration of perpetrators in the Rwanda society.

\author{
Author affiliations \\ 1 Department of Epidemiology and Biostatistics, University of Rwanda College of \\ Medicine and Health Sciences, School of Public Health, Kigali, Rwanda \\ ${ }^{2}$ Rwanda National Police, Directorate of Medical Service, Kigali, Rwanda \\ ${ }^{3}$ Department of Global Health and Social Medicine, Harvard Medical School, \\ Boston, USA \\ ${ }^{4}$ Oregon Health \& Science University, School of Medicine, Portland, Oregon, USA \\ ${ }^{5}$ Faculty of Medicine, Section of Forensic Medicine, Umeå University, Umeå, Sweden \\ ${ }^{6}$ Faculty of Health Sciences, Department of Forensic Medicine, Aarhus University, \\ Aarhus, Denmark
}

Acknowledgements We thank police criminal investigators and nurses of police health centres who assisted in data collection. We are very grateful to the Center for Diseases Control and Prevention and WHO for their invaluable financial and technical support that enabled us to conduct this study. We thank Dr Molly Franke and Dr Megan Murray for their technical review and feedback on the paper.

Contributors WR led all aspects of this paper, from study design to data collection, analysis and manuscript preparation. BLH-G, JN and MDF all provided direct supervision to WR as part of his PhD programme at the University of Rwanda College of Medicine and Health Sciences School of Public Health. All authors participated in data interpretation and preparation of the manuscript and approved the final version of this paper.

Funding This study was funded by the World Health Organization. Project No: AFRWA 1005685, AWARD No: 53975. BLH-G received support from the Department of Global Health and Social Medicine Research Core at Harvard Medical School.

Competing interests WR received support from the US Centers for Disease Control and Prevention.

Ethics approval Institutional Review Board of the School of Public Health, College of Medicine and Health Sciences, Rwanda University.

Provenance and peer review Not commissioned; externally peer reviewed.

Data sharing statement The data that we collected will be made available to the Government of Rwanda; whoever wants the data should make a request to the Government of Rwanda through existing channels.

Open Access This is an Open Access article distributed in accordance with the Creative Commons Attribution Non Commercial (CC BY-NC 4.0) license, which permits others to distribute, remix, adapt, build upon this work non-commercially, and license their derivative works on different terms, provided the original work is properly cited and the use is non-commercial. See: http://creativecommons.org/ licenses/by-nc/4.0/

\section{REFERENCES}

1 Dyregrov A, Gupta L, Gjestad R, et al. Trauma exposure and psychological reactions among Rwandan children. J Trauma Stress 2000;13:3-21.

2 Rieder $\mathrm{H}$, Elbert T. Rwanda-lasting imprints of genocide: trauma, mental health and psychological conditions in survivors, former prisoners and their children. Confl Health 2013:7:6.

3 Kavuro C. Rwanda Reconciliation Process: Outcome Analysis of Gacaca Courts. Great Lakes Region Shareholders' Conference for Sustainable Peace Conference. Center for the Book, Cape Town, 2011.
4 Sosnov M, Ball H. The adjudication of genocide: Gacaca and the road to reconciliation in Rwanda. J Intern Law Policy 2008;36:2

5 Farhood L, Dimassi H, Lehtinen T. Exposure to war-related traumatic events, prevalence of PTSD, and general psychiatric morbidity in a civilian population from Southern Lebanon. J Transcult Nurs 2009;17:333-40.

6 Krysinska K, Lester D, Martin G. Suicidal behavior after a traumatic event. J Trauma Nurs 2009;16:103-10.

7 Knox KL. Epidemiology of the relationship between trauma experience and suicidal behaviors. National Center for PTSD. PTSD Research Quartery. Vermont, National Center for PTSD, 2008.

8 Handicap International. Healing individual trauma by reweaving social and community ties. An example of community approach in mental health after the genocide against Tutsi in Rwanda 2009. Kigali: HI, 2009 (in French).

9 Clarke DE, Colantonio A, Heslegrave R, et al. Holocaust experience and suicidal ideation in high-risk older adults. Am J Geriatr Psychiatry 2004; 12:65-74.

10 Barak Y, Aizenberg D, Szor H, et al. Increased risk of attempted suicide among aging Holocaust survivors. Am J Geriatr Psychiatry 2005;13:701-4.

11 Institute of Research and Dialogue for Peace (IRDP). Mechanisms to fight against the negation of the Tutsi genocide. Research Report 2008, Kigali: IRDP, 2008.

12 United Nations Security Council. Resolutions and statements on DRC. New York, January 29, 2014, resolution 2136

13 Rieder $\mathrm{H}$, Elbert T. Rwanda-lasting imprints of a genocide: trauma, mental health and psychosocial conditions in survivors, former prisoners and their children. Confl Health 2013;7:6.

14 Krysinska K, Lester D. Suicide in the Lodz ghetto 1941-44. Pol Psychol Bull 2002;33:21-6.

15 Leenaars AA, Brown C, Taparti L, et al. Genocide and suicide among indigenous people: the North meets the South. Can I Native Stud 19:337-63.

16 Human Right Watch. Rwanda country summary. World Report 2011, New York: HRW, 2011

17 Kiyanda E, Wamala D, Musisi S, et al. Suicide in urban Kampala, Uganda: a preliminary exploration. Afr Health Sci 2011;11:219-27.

18 Blakely T, Collings S, Atkinson J. Unemployment and suicide. Evidence for a causal association? J Epidemiol Community Health 2003;57:594-600.

19 Hunt IM, Kapur N, Webb R, et al. Suicide in recently discharged psychiatric patients: a case-control study. Psychol Med 2009;39:443-9.

20 Almassi K, Belso N, Kapur N, et al. Risk factors for suicide in Hungary. A case control study. BMC Psychiatry 2009,9:45.

21 Phillips MR, Yang G, Zhang Y, et al. Risk factors for suicide in China: a natural case-control psychological autopsy study. Lancet 2002;360:1728-35.

22 Manoranjitham SD, Rajkumar AP, Thagandurai $P$, et al. Risk factors for suicide in rural India. Br J Psychiatry 2010;196:26-30.

23 Meel BL. Suicide and HIV/AIDS in Transkei, South Africa.Anil Aggrawal's Internet J Forensic Med Toxicol 2003;4:1. http://www.anilaggrawal.com/ij/vol_004_no_001/ papers/paper001.html. (accessed 23 Jun 2013).

24 Yang GH, Phillips MR, Zhou MG, et al. Understanding the unique characteristics of suicide in China: national psychological autopsy study. Biomed Environ Sci 2005; 18:379-89

25 Knox KL, Conwell Y, Caine ED. If suicide is a public health problem, what are we doing to prevent it? Am J Public Health 2004;94:37-45.

26 Miller M, Hamenway D, Azrael D. Firearms and suicide in the Northeast. I Trauma 2004:57:626-32.

27 Center for Control Diseases and Prevention. National Center for Injury Prevention and Control. Division of Violence Prevention Suicide due to alcohol and/or drug overdose. A data brief from the national violent death reporting system. http://www.cdc.gov/violenceprevention/pdf/NVDRS_Data_Brief-a.pdf (accessed 22 Jun 2013).

28 Agerbo E, Qin P, Mortensen B. Psychiatric illness, socioeconomic status, and marital status in people committing suicide: a matched case- sibling-control study. J Epidemiol Community Health 2006;60:776-81.

29 Karl Foster. Doctoral Thesis, Criminal law. The Khmer Rouge and the Crime of Genocide. Issues of Genocide Intent With Regard to the Khmer Rouge Mass Atrocities. Berne: University of Berne, 2011.

30 Winton MA, Unlu A. Micro-macro dimensions of the Bosnian genocides: the circumplex model and violentization theory. Elsevier.ScienceDirect. Aggression Violent Behav 2008;13:45-59. 